\title{
Role of pigment epithelium-derived factor in the reproductive system
}

\author{
Dana Chuderland, Ido Ben-Ami ${ }^{1}$, Hadas Bar-Joseph and Ruth Shalgi \\ Department of Cell and Developmental Biology, Sackler Faculty of Medicine, Tel-Aviv University, Ramat-Aviv, \\ Tel-Aviv 69978, Israel and ${ }^{1}$ IVF and Infertility Unit, Department of Obstetrics and Gynecology, Assaf Harofeh Medical \\ Center (Affiliated with the Sackler Faculty of Medicine, Tel-Aviv University), Zerifin 70300, Israel
}

Correspondence should be addressed to R Shalgi; Email: shalgir@post.tau.ac.il

\begin{abstract}
The physiological function of the female reproductive organs is hormonally controlled. In each cycle, the reproductive organs undergo tissue modifications that are accompanied by formation and destruction of blood vessels. Proper angiogenesis requires an accurate balance between stimulatory and inhibitory signals, provided by pro- and anti-angiogenic factors. As with many other tissues, vascular endothelial growth factor (VEGF) appears to be one of the major pro-angiogenic factors in the female reproductive organs. Pigment epithelium-derived factor (PEDF) is a non-inhibitory member of the serine protease inhibitors (serpin) superfamily, possessing potent physiologic anti-angiogenic activity that negates VEGF activity. The role of PEDF in decreasing abnormal neovascularization by exerting its anti-angiogenic effect that inhibits pro-angiogenic factors, including VEGF, has been investigated mainly in the eye and in cancer. This review summarizes the function of PEDF in the reproductive system, showing its hormonal regulation and its anti-angiogenic activity. Furthermore, some pathologies of the female reproductive organs, including endometriosis, ovarian hyperstimulation syndrome, polycystic ovary syndrome, and others, are associated with a faulty angiogenic process. This review illuminates the role of PEDF in their pathogenesis and treatment. Collectively, we can conclude that although PEDF seems to play an essential role in the physiology and pathophysiology of the reproductive system, its full role and mechanism of action still need to be elucidated.
\end{abstract}

Reproduction (2014) 148 R53-R61

\section{Introduction}

Pigment epithelium-derived factor (PEDF), encoded by SERPINF1 gene, is a secreted glycoprotein that belongs to the non-inhibitory members of the serine protease inhibitors (serpin) superfamily (Becerra et al. 1995). PEDF was first purified by Tombran-Tink et al. (1991) from conditioned media of human retinal pigment epithelium and identified as a neurotrophic agent capable of converting Y79 retinoblastoma tumor cells into differentiated non-proliferative neurons (Steele et al. 1993).

Later, Dawson et al. (1999) showed that besides its neurotrophic properties, PEDF can also act as a potent inhibitor of angiogenesis. PEDF was first characterized as an anti-angiogenic factor that regulates the vascularity of ocular compartments in the eye (Bouck 2002). It was shown to be involved in the pathogenesis of angiogenic eye diseases, such as proliferative diabetic retinopathy and others (Volpert et al. 2002). The anti-angiogenic activity of PEDF was found to be selective and reversible; i.e., it targets only newly forming vessels, spares the existing ones, and does not interfere in the transient vigorous creation of new vessels needed, for example, in times of injury (Bouck 2002). It is clear today that PEDF is expressed throughout the body and regulates angiogenesis; its level was found to be altered under pathological conditions in which unrestrained angiogenesis is involved, such as cancer, diabetes, endometriosis, ovarian hyper-stimulation, and more (Becerra \& Notario 2013, Chuderland et al. 2013a). Finally, PEDF is accepted as one of the most potent anti-angiogenic factors in the body, hence it can be considered as a highly effective treatment of angiogenesis-related pathologies. In this review, we focus on the role of PEDF in the reproductive system, as an anti angiogenic physiological-regulator and as a potential therapeutic agent.

\section{PEDF post-translational modifications}

Most cells express PEDF transcripts, and the mature gene product is mainly secreted as a soluble monomeric glycoprotein (Becerra \& Notario 2013). PEDF undergoes $\mathrm{N}$-glycosylation that occurs at the Asn285 site. In addition, Maik-Rachline et al. (2005) demonstrated that PEDF is a phosphoprotein, which has several phosphorylation sites that determine its function as either neurotrophic or anti-angiogenic (Maik-Rachline \& Seger 2006). The neurotrophic activity is mediated by PKA 
that phosphorylates PEDF on Ser 227, whereas the anti-angiogenic activity is mediated by CK2 that phosphorylates PEDF on Ser 24 and Ser 114. In addition, induction of PKA followed by CK2 phosphorylation exhibits its most potent anti-angiogenic and neurotrophic activities (Maik-Rachline \& Seger 2006). On top of its neurotrophic and anti-angiogenic activities (Simonovic et al. 2001), PEDF was shown to function as an anti-inflammatory (Wang et al. 2008) and anti-oxidative factor (Yamagishi et al. 2005, Bar-Joseph et al. 2014).

\section{PEDF receptors}

The multiplicity of PEDF functions lead the researchers to assume that there is more than one receptor for PEDF, which cater to its different functions (Maik-Rachline \& Seger 2006). Up to date, several putative receptors have been suggested to take part in PEDF mechanism of action that includes: patatin-like phospholipase domaincontaining 2 (PNPLA2; PEDF- $\mathrm{R}^{\mathrm{N}}$ ), that is involved in neurotrophic activity of PEDF; laminin receptor (LR PEDF-R ${ }^{A}$; (Alberdi et al. 1999, Bernard et al. 2009, Filleur et al. 2009)); lipoprotein receptor-related protein 5 (LPR5; Wnt co-receptor (Anne et al. 2013))); and cell surface F1F0-ATP synthase (Notari et al. 2010) that mediates PEDF anti-angiogenic activity.

\section{PEDF and vascular endothelial growth factor}

Growing amount of evidence indicates that under physiological conditions, a delicate balance exists between PEDF and vascular endothelial growth factor (VEGF), and that PEDF may counteract the pro-angiogenic activity of VEGF. For example, in adult retinal pigment epithelial cells, oxidative stress conditions reduce the level of PEDF without affecting VEGF level, thereby disrupting the angiogenic balance between PEDF and VEGF, giving a selective advantage to the angiogenicpromoting activity (Ohno-Matsui et al. 2001) that can lead to the development of choroidal neovascularization in age-related macular degeneration (AMD). Treatment with recombinant PEDF (rPEDF) restored the angiogenic balance and by that alleviated AMD symptoms (Popp et al. 2013). In addition, the balance between PEDF and VEGF affects the fate of fibroblasts, where high PEDF level and low VEGF level are correlated with fibroblast quiescence; once the cells start to divide, the ratio is reversed. However, this controlled reversible angiogenic balance is interrupted in tumor-associated angiogenesis in a manner that resetting the 'angiogenic switch' is no longer possible (Pollina et al. 2008).

Our knowledge regarding the mechanism by which PEDF regulates VEGF is still evolving; in bovine retinal microvascular endothelial cells, PEDF regulates the translocation of the intracellular domain of VEGF receptor 1 (VEGFR1) and its phosphorylation, destructing the ability of VEGFR2 to induce angiogenesis (Cai et al. 2006). In porcine retinal endothelial cells, it was suggested that PEDF inhibits VEGF-induced vascular permeability and angiogenesis through the SRC kinase pathway (Sheikpranbabu et al. 2010). In cancer cells, PEDF affects VEGF activity indirectly by downregulating the expression of HIF1 $\alpha$ (Yang et al. 2009). Other studies conducted in endothelial cells showed that survival and apoptotic cascades occur simultaneously within a single cell; the switch between the processes depends on changes in the balance between PEDF and VEGF (Pollina et al. 2008). However, detailed studies are still required to fully understand the mechanism behind these networks (Manalo et al. 2011).

\section{Angiogenesis in the reproductive system}

Angiogenesis in adults is usually in a quiescent state, with the exception of the female reproductive system and wound healing (Fraser \& Lunn 2000). To achieve a proper angiogenesis, an accurate balance between proand anti-angiogenic factors must be maintained (Manalo et al. 2011); any failure in angiogenesis can lead to diverse pathologies.

The female reproductive system (i.e., ovaries and uterus), unlike any other organ, undergoes cyclic modifications orchestrated by alternating periods of hormonal stimulation and angiogenesis. On the one hand, the development of new blood vessels in the ovary and uterus is essential to guarantee the necessary supply of nutrients and hormones (Shimizu et al. 2012) that allows oocyte maturation and supports embryo implantation and early pregnancy. On the other hand, destruction of blood vessels is a crucial step that terminates one reproductive cycle and embarks on the next one. This dynamic angiogenesis is regulated by a balance between pro- and anti-angiogenic factors. Like in many other tissues, VEGF appears to be one of the major pro-angiogenic factors in the female reproductive organs (Fraser 2006); however, less is known regarding the anti-angiogenic factors.

The expression of PEDF in various fetal and adult human tissues was examined more than a decade ago by multi-tissue northern blotting assays. This analysis demonstrated a dominant expression of PEDF in the reproductive system organs; though, the function of PEDF in these organs remained obscure till recently. The potent anti-angiogenic nature of PEDF and its ability to regulate VEGF activity make this protein a potential regulating factor in the reproductive system. Understanding the balance between PEDF and VEGF in the reproductive system may help to decipher the pathophysiology of reproductive angiogenesis-related reproductive pathologies and hint at a new therapeutic approach. 


\section{The role of PEDF in ovarian physiology and pathology}

Stromal blood vessels are the follicular source of nutrients and oxygen, which passively diffuse into primordial and primary follicles. The follicular growth is associated with the development of an autonomous blood capillary network that is restricted to the outer theca layer. The granulosa cells layer becomes vascular only after ovulation toward creation of the corpus luteum (CL). The entire process of CL formation is accompanied by sprouting of blood vessels toward the intrafollicular granulosa cells (Phan et al. 2006). Thus, a tight regulatory mechanism to supervise the process is mandatory. It was shown that endothelial cells undergo proliferation while incubating in a conditioned culture medium of the theca cells derived from follicles of all developmental stages. However, the response of endothelial cells to granulosa cells conditioned culture medium was dependent on follicle developmental stage: inhibited by follicular-phase granulosa cells and stimulated by pre-ovulatory granulosa cells, just before the follicle turns into a highly vascular CL (Gruemmer et al. 2005, Fraser 2006). These observations indicate the existence of a modular switch between pro- and anti-angiogenic factors in granulosa cells. Till recently most of the research has been directed toward characterization of ovarian pro-angiogenic factors, predominantly the VEGF family (Ferrara 2004). The most significant member of the family is VEGF-A (hereafter VEGF), which is produced in a number of isoforms, VEGF 165 being the most prominent in the ovary (Tesone et al. 2005). Studies have shown that inhibition of VEGF and VEGFR2 can impair follicular development or prevent ovulation (Fraser 2006). However, even after 70 years of research, the literature dealt more with the nature of the physiological pro-angiogenic factor of the ovary than with that of the anti-angiogenic one. Two anti-angiogenic candidates were suggested, thrombospondin (TPS; Osz et al. 2014) and hyaluronic acid (Tempel et al. 2000). TPS was found to be expressed in and secreted from granulosa cells regulated by gonadotropins. Knockout of TPS receptor has been correlated with increased ovarian vascularization and VEGF expression (Osz et al. 2014). Hyaluronic acid, which is produced by cumulus cells, inhibits the activity of endothelial cells in vitro, an activity that is not hormonally regulated (Tempel et al. 2000).

The expression of PEDF in the ovary was first reported by Cheung et al. (2006), showing that silencing PEDF expression can cause carcinogenesis of ovarian surface epithelium. Recently, we have characterized the physiological role of PEDF in the ovary, showing that PEDF is expressed in human and rodent ovaries, produced and secreted by granulosa cells in a hormonally dependent manner (Chuderland et al. 2013b). The secreted PEDF possesses an anti-angiogenic effect, as demonstrated by in vitro inhibition of human umbilical vein endothelial cells (HUVECs) proliferation, migration, and tube formation. We found that mimicking in vitro the hormonal changes occurring around ovulation; namely, an increase in estradiol $\left(E_{2}\right)$ level, upregulation of luteinizing hormone, and an increase in progesterone $\left(\mathrm{P}_{4}\right)$ level, led to the downregulation of PEDF expression and secretion. As in other tissues, we have further demonstrated that the expression of PEDF is inverse to that of VEGF; human chorionic gonadotropin (hCG) causes a decrease in the expression of PEDF and an increase in the expression of VEGF, both in vivo and in vitro (Chuderland et al. 2013a). We and others have shown that granulosa cells express PEDF- $\mathrm{R}^{\mathrm{N}}$ (Kampfer et al. 2014) and that in vitro stimulation with rPEDF downregulates VEGF mRNA synthesis in a dosedependent manner (Chuderland et al. 2013a). The direct in vitro effect of rPEDF on VEGF biosynthesis in granulosa cells suggests that PEDF, produced by granulosa cells, exerts its effects in an autocrine or/and paracrine fashion.

Several reproductive disorders are associated with impaired ovarian angiogenesis; two distinct ones are ovarian hyperstimulation syndrome (OHSS) and polycystic ovary syndrome (PCOS). OHSS is associated with unrestrained formation of blood vessels and increased capillary permeability; PCOS is characterized with an excessive vascular formation (Amin et al. 2003). Thus, the development of therapies to these syndromes depends mainly on understanding the mechanism of ovarian angiogenesis (Soares 2011). OHSS is an iatrogenic complication, caused by ovarian stimulation with exogenous gonadotropins and ovulation induction by hCG to trigger oocyte maturation, particularly during IVF treatments (Humaidan et al. 2010). OHSS appears to be induced by ovarian release of vasoactive, angiogenic substances that cause extensive angiogenesis, vascular hyper-permeability, leakage, and extravagation of fluids from the blood vessels into the extravascular space with consequent clinical manifestations of ascites and edema (Albert et al. 2002). The pathophysiology of OHSS is not fully clear, though it is known that impaired angiogenic balance lies at the core of the syndrome and women with PCOS are at high risk to develop OHSS. Other conditions that are associated with OHSS are as follows: large number of recruitable follicles, high $\mathrm{E}_{2}$ level, rapidly increasing $E_{2}$ level, size and number of stimulated follicles, number of oocytes retrieved, low body weight, and BMI. VEGF is considered to be the main factor that causes increased vascular permeability and a hallmark for OHSS in humans and rodents (Bates \& Harper 2002). Increased VEGF levels in both serum and ovaries were associated with a higher probability of developing OHSS and its clinical manifestations (Soares 2011). We have recently shown that PEDF takes part in the pathogenesis of OHSS (Chuderland et al. 2013a); reduced level of PEDF was detected in the ovaries of mice stimulated to develop OHSS (Fig. 1). Given that OHSS may be a life threatening syndrome, many suggestions how to bypass the syndrome have been 


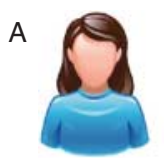

Risk factors

- Large number of recruitable follicles

- High estradiol levels

- Rapidly increasing estradiol levels

- Number of oocytes retrieved

- PCOS

- History of previous OHSS

- Lean body weight and BMI

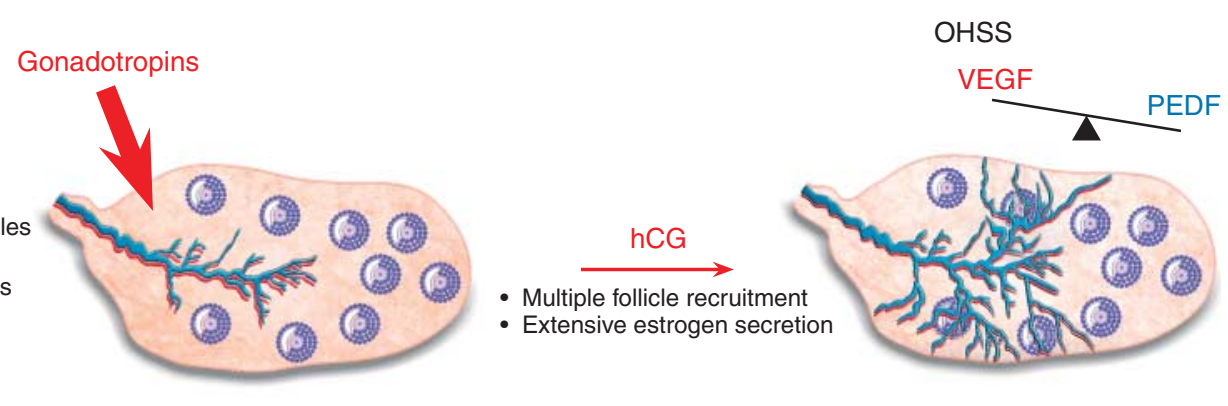

B

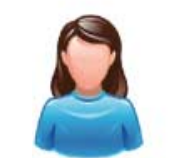

Risk factors

- Large number of recruitable follicles

- High estradiol levels

- Rapidly increasing estradiol levels

- Number of oocytes retrieved

- PCOS

- History of previous OHSS

- Lean body weight and BMI

Figure 1 OHSS pathophysiology and treatment. (A) Pathophysiology - IVF treatment, which includes stimulation with gonadotropins, may result in increased number of recruited follicles and thereby elevation of secreted $E_{2}$. Stimulation by hCG increases the level of VEGF and decreases that of PEDF, thereby causing ovarian hyper-vascularization; OHSS. (B) Treatment - treatment with recombinant PEDF along with gonadotropins prevents excess production of VEGF, thereby preventing ovarian hyper-vascularization; OHSS prevention.

made during the years by both basic scientists and clinicians. Triggering ovulation by gonadotropinreleasing hormone analog instead of hCG and in vitro oocyte maturation were two of the clinical suggestions to avoid the risk of developing OHSS, though both dramatically decreased pregnancy rate (Humaidan et al. 2005, de Ziegler et al. 2012). Researchers suggested therapeutic approach for OHSS by targeting the VEGF pathway; for example, the use of SU5416, a synthetic compound developed to inhibit angiogenesis in cancer patients through the VEGF pathway. This compound was highly effective in the treatment of OHSS induced in mice (Gomez et al. 2002), but, the severe side-effects caused by SU5416, and the concern that it might interfere with early pregnancy, ruled it out from use in otherwise healthy women (Kuenen et al. 2003). The use of dopamine agonists that inhibit the phosphorylation of VEGFR2, and thereby can selectively inhibit VEGFinduced vascular permeability in OHSS, has been suggested recently. The tolerability of dopamine agonists among patients and the fact that they do not interfere with IVF outcome make them a promising treatment for OHSS (Soares 2011). Recent meta-analysis of nine studies concluded that dopamine agonist may prevent OHSS; however, it was found to be less effective for the treatment of OHSS (Baumgarten et al. 2013). We showed that replacement therapy with rPEDF alleviates OHSS signs in a mouse model. Administration of rPEDF together with high doses of gonadotropins prevented weight gain, ovarian enlargement, and vascular hyperpermeability by inhibiting the excessive expression of VEGF. Furthermore, we found that administration of rPEDF had no negative effect on ovulation, implantation, and ongoing pregnancy. These findings may suggest a possible therapeutic advantage of rPEDF in OHSS because it restores the level of VEGF to the physiological range without impairing its normal functions, as is evident in both in vitro and in vivo experiments. We hypothesize that PEDF alleviates OHSS by suppressing VEGF, though this still needs to be proven (Fig. 1).

PCOS is currently the most common endocrine disorder in women of reproductive age (about 7-10\% of women worldwide). The pathophysiology of this syndrome is not fully understood though several risk factors were found to be associated: genetic background, metabolic disorders (insulin resistance (IR) and hyperinsulinemia), and the in utero environment (Nandi et al. 2014). Increased production and secretion of ovarian VEGF is common in women suffering from this disease. VEGF overproduction is thought to be a trigger for the development of OHSS, frequently seen in this group of patients (Gomez et al. 2011). In 2011, PEDF was suggested to take part in the pathogenesis of PCOS (Yang et al. 2011), where it was shown that elevated level of 
PEDF in the serum is associated with IR and PCOS; however, the conclusion of this study was challenged because of the small group of patients. In 2012, it was reported that PEDF level in the serum of PCOS patients is not elevated (Joham et al. 2012). The authors showed that the increased level of PEDF in the serum is associated with metabolic risk factors such as IR, but PEDF level was not altered compared with the matching controls (age and BMl; Lecke et al. 2013). Finally, in 2013, it was reported that changes in the level of PEDF in the serum of women with PCOS was closely associated with inflammation processes (Cheng et al. 2013). Under other, not related pathologies, it was demonstrated that changes in serum PEDF level are not necessarily reflected in its level in organs of interest (Katakami et al. 2008). We demonstrated an increased level of VEGF and a decreased level of PEDF in ovaries of PCOSinduced mice (Fig. 2); namely, a change in the physiological balance of PEDF and VEGF that can theoretically be shifted back by exogenous treatment with rPEDF. However, a broader scope research is needed to clarify the role of PEDF in PCOS pathogenesis and its therapeutic potential.

\section{The role of PEDF in endometrial physiology and pathology}

The human endometrium undergoes extensive cyclic morphological and biochemical modifications during each menstrual cycle of a woman's fertile life. These modifications include regeneration, breakdown, and shedding of the endometrial tissue; all regulated by the ovarian steroids $\mathrm{E}_{2}$ and $\mathrm{P}_{4}$ and their receptors (Smith 2001). However, up to date it is not clear how these

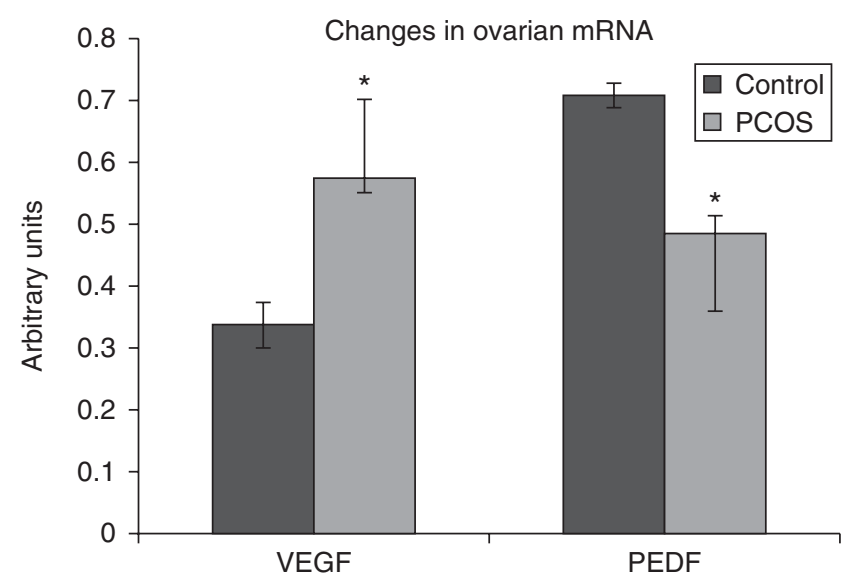

Figure 2 Counter regulation of PEDF/VEGF levels in PCOS. Pregnant ICR mice were administered once daily with di-hydro-testosterone (PCOS; $n=4$ ) or with oil (control; $n=4$ ) on days 16-19 of pregnancy. Female offsprings were allowed to grow to reproductive age (8 weeks). Ovaries were subjected to real-time PCR analysis with specific primers for PEDF or VEGF; calibrated with HPRT. *Significantly different from control value $(P<0.05)$. steroids specifically regulate endometrial angiogenesis, mainly due to species-related variations as well as timing deviations and different experimental designs (Girling et al. 2007, Das et al. 2009). The pro-angiogenic activity of $E_{2}$ was suggested in mice, null for estrogen receptor $\alpha$ that failed to develop uterine angiogenesis (Johns et al. 1996), and in ovariectomized mice that showed a rapid proliferation of endometrial endothelial cells under $E_{2}$ stimulation (Heryanto \& Rogers 2002). The role of $\mathrm{P}_{4}$ in endometrial angiogenesis is less established. In vivo studies show that administration of $\mathrm{P}_{4}$ combined with low doses of $E_{2}$ inhibited endothelial cells proliferation; but upon its administration with high doses of $E_{2}$, proliferation of endometrial endothelial cells was significantly increased (Heryanto \& Rogers 2002). The effects of $E_{2}$ and $P_{4}$ are attributed to differential spatiotemporal expressions of pro-angiogenic factors in the uterus (VEGF, angiogenin, fibroblast growth factors, and others; Girling \& Rogers 2009). As in the ovary, the best characterized pro-angiogenic factors are the members of the VEGF family. Various studies have demonstrated the presence of different VEGF isoforms in the endometrium (Ancelin et al. 2002), including VEGF 165, VEGF 121, VEGF 145, and VEGF 189, all regulated by hormones. VEGF 165 is believed to be the dominant isoform in human endometrium, as it is in the ovary, and its expression is altered dynamically during the menstrual cycle (Lash et al. 2012). Yet, the specific mechanisms leading to angiogenesis, migration, and/or proliferation of endometrial endothelial cells still need to be elucidated (Girling \& Rogers 2009).

The first report for PEDF function in the endometrium was given by Palmieri et al. (1999); they followed agerelated changes in the level of PEDF and their effect on tumorigenicity. This group reported that PEDF level decreased with age and suggested that this decrease can contribute to the age-related increase in cancer incidence. When characterizing the physiological role of PEDF in the uterus, we found that PEDF is dynamically expressed in the endometrium of humans and rodents during the menstrual and estrus cycles, respectively (Chuderland et al. 2013c, 2014), in a reciprocal manner to VEGF expression. Using a mouse model and human endometrial cell line, we found that $E_{2}$ and $P_{4}$ regulate the expression of PEDF. $E_{2}$ induces a decrease in PEDF level, whereas $\mathrm{P}_{4}$ administered after $\mathrm{E}_{2}$ priming induces an increase. We have further demonstrated the expression of PEDF- $\mathrm{R}^{\mathrm{N}}$ in human endometrium, localized mainly at the endometrial glands, and showed that rPEDF downregulates VEGF expression in vitro (Chuderland et al. 2014).

During the last decade, it had become clear that endometrial angiogenesis is a multi-step, multi-factorial process (Girling \& Rogers 2005). Abnormal endometrial angiogenesis may contribute to the development of several endometrium-related pathologies - including endometrial cancer (Weigelt \& Banerjee 2012), 
endometriosis (Soares et al. 2012), menorrhagia (Bouchard 2011), breakthrough bleeding (Lockwood 2011), and repeated implantation failure, secondary to impaired endometrial receptivity (Torry et al. 2007).

Endometriosis is a gynecological condition in which endometrial tissue (lesions) is present outside of the uterus usually on the peritoneum and ovaries, and is associated with infertility, dysmenorrhea, dyspareunia, and chronic pelvic pain. This pathology is rather common among reproductive-age women $(10 \%)$ and even more among infertile women (50\%; Mansour et al. 2010). Though the necessity of angiogenesis and the involvement of VEGF (Laschke et al. 2011) in the development and maintenance of endometrial lesions outside the uterus are clear, not much is known regarding the mechanisms behind the process (Soares et al. 2012). Yet, one can postulate that PEDF/VEGF balance is important for the maintenance of normal endometrium functions, and that impairment of the physiological equilibrium may be associated with angiogenesisrelated endometrial pathologies as endometriosis. The expression level of PEDF was found to be significantly lower in the endometrium (Sun et al. 2012), endometrial lesions (Sun et al. 2012), peritoneal fluid (Chen et al. 2011) and serum (Chen et al. 2012) of women with endometriosis than that in the same organs of healthy women. On the other hand, whether VEGF is elevated in women suffering from endometriosis is still debatable (May et al. 2010).

To date, the two endometriosis therapeutic approaches are either induction of an amenorrheic hypoestrogenic state, by suppressing ovarian estrogen secretion or surgery; both of them are not recommended to women planning pregnancy (de Ziegler et al. 2010). Thought it is clear that a specific anti-angiogenic therapy may be the solution to this syndrome, the current available anti-VEGF drugs induce severe side effects.

Dopamine agonist was also suggested as a treatment for endometriosis. However, not only does dopamine have unpleasant side effects, it also lacks the ability, at least in mice, to reduce the size of endometrial lesions, by more than $30 \%$. To date, there is only a single non-randomized pilot study carried out in ten human patients, showing a decrease in lesions area, 18-20 weeks after initiation of dopamine treatment (Soares et al. 2012). We (Chuderland etal. 2013c) and others (Chen etal. 2011, Zhao etal. 2012) have recently suggested the use of PEDF for treating endometriosis. Sun et al. (2012) showed that PEDF gene treatment inhibits the growth of human endometriotic cells in vivo when transplanted to a nude mouse model; they have further showed that this treatment reduces VEGF level and angiogenesis in the lesion (Sun et al. 2012, Zhao et al. 2012). We showed that treatment with rPEDF eradicates endometrial lesions as well as causes a significant decrease in the level of VEGF in the lesions. An egg factor is also a symptom of women suffering from endometriosis (Barcelos et al. 2009). We found that rPEDF treatment improved significantly ovulation rate of rats with induced endometriosis (Chuderland et al. 2013c); yet, a more extensive research regarding the functions of PEDF in the reproductive system needs to be carried out in order to clarify whether it can improve oocyte quality.

\section{Conclusion and prospective}

Angiogenesis is an essential process in the women reproductive system. This is a tightly regulated mechanism orchestrated by pro- and anti-angiogenic factors. Angiogenesis lies also at the core of several reproductive-associated disorders. Though PEDF was characterized as one of the most potent anti-angiogenic factors in the body, its function in the reproductive system was neglected, and up until recently there were virtually no data regarding its putative role/s. We have recently started to characterize PEDF regulation and function in the reproductive system, showing its dynamic expression during the hormonal/menstrual cycle. We have also illustrated its therapeutic potential for treating these pathologies. On top of PEDF antiangiogenic activity, this protein is known to possess anti-inflammatory (Wang et al. 2008) and anti-oxidative properties (Yamagishi et al. 2005), both are important processes involved in the physiological regulation of the female reproductive system. Oxidative stress and inflammation were found to be correlated with infertility in women, leading us to hypothesize that PEDF can serve also as a gonadal protectant. However, in order to understand and to benefit from PEDF function in the reproductive system its mechanism of actions needs to be illustrated. Revealing the complexity of PEDF regulation in the reproductive system can shed light on diverse reproductive-related pathologies as well as their potential therapies.

\section{Declaration of interest}

The authors declare that there is no conflict of interest that could be perceived as prejudicing the impartiality of the review.

\section{Funding}

This work was partially supported by German Israel foundation no. I-2318-1084.2/2012.

\section{References}

Alberdi E, Aymerich MS \& Becerra SP 1999 Binding of pigment epitheliumderived factor (PEDF) to retinoblastoma cells and cerebellar granule neurons. Evidence for a PEDF receptor. Journal of Biological Chemistry 274 31605-31612. (doi:10.1074/jbc.274.44.31605)

Albert C, Garrido N, Mercader A, Rao CV, Remohi J, Simon C \& Pellicer A 2002 The role of endothelial cells in the pathogenesis of ovarian hyperstimulation syndrome. Molecular Human Reproduction 8 409-418. (doi:10.1093/molehr/8.5.409) 
Amin AF, Abd el-Aal DE, Darwish AM \& Meki AR 2003 Evaluation of the impact of laparoscopic ovarian drilling on Doppler indices of ovarian stromal blood flow, serum vascular endothelial growth factor, and insulin-like growth factor- 1 in women with polycystic ovary syndrome. Fertility and Sterility 79 938-941. (doi:10.1016/S00150282(02)04849-5)

Ancelin M, Buteau-Lozano H, Meduri G, Osborne-Pellegrin M, Sordello S, Plouet J \& Perrot-Applanat M 2002 A dynamic shift of VEGF isoforms with a transient and selective progesterone-induced expression of VEGF189 regulates angiogenesis and vascular permeability in human uterus. PNAS 99 6023-6028. (doi:10.1073/pnas.082110999)

Anne SL, Govek EE, Ayrault O, Kim JH, Zhu X, Murphy DA, Van Aelst L, Roussel MF \& Hatten ME 2013 WNT3 inhibits cerebellar granule neuron progenitor proliferation and medulloblastoma formation via MAPK activation. PLoS ONE 8 e81769. (doi:10.1371/journal.pone.0081769)

Barcelos ID, Vieira RC, Ferreira EM, Martins WP, Ferriani RA \& Navarro PA 2009 Comparative analysis of the spindle and chromosome configurations of in vitro-matured oocytes from patients with endometriosis and from control subjects: a pilot study. Fertility and Sterility 92 1749-1752. (doi:10.1016/j.fertnstert.2009.05.006)

Bar-Joseph H, Ben-Ami I, Ron-El R, Shalgi R \& Chuderland D 2014 Pigment epithelium derived factor (PEDF) exerts antioxidative effects in granulosa cells. Fertility and Sterility 102 891-898.e3. (doi:10.1016/j.fertnstert. 2014.06.012)

Bates DO \& Harper SJ 2002 Regulation of vascular permeability by vascular endothelial growth factors. Vascular Pharmacology 39 225-237. (doi:10.1016/S1537-1891(03)00011-9)

Baumgarten M, Polanski L, Campbell B \& Raine-Fenning N 2013 Do dopamine agonists prevent or reduce the severity of ovarian hyperstimulation syndrome in women undergoing assisted reproduction? A systematic review and meta-analysis Human Fertility 16 168-174. (doi:10.3109/14647273.2013.833348)

Becerra SP \& Notario V 2013 The effects of PEDF on cancer biology: mechanisms of action and therapeutic potential. Nature Reviews. Cancer 13 258-271. (doi:10.1038/nrc3484)

Becerra SP, Sagasti A, Spinella P \& Notario V 1995 Pigment epitheliumderived factor behaves like a noninhibitory serpin. Neurotrophic activity does not require the serpin reactive loop. Journal of Biological Chemistry 270 25992-25999. (doi:10.1074/jbc.270.43.25992)

Bernard A, Gao-Li J, Franco CA, Bouceba T, Huet A \& Li Z 2009 Laminin receptor involvement in the anti-angiogenic activity of pigment epithelium-derived factor. Journal of Biological Chemistry 284 10480-10490. (doi:10.1074/jbc.M809259200)

Bouchard P 2011 Current and future medical treatments for menometrorrhagia during the premenopause. Gynecological Endocrinology 27 (Suppl 1) 1120-1125. (doi:10.3109/09513590.2012.638754)

Bouck N 2002 PEDF: anti-angiogenic guardian of ocular function. Trends in Molecular Medicine 8 330-334. (doi:10.1016/S1471-4914(02)02362-6)

Cai J, Jiang WG, Grant MB \& Boulton M 2006 Pigment epithelium-derived factor inhibits angiogenesis via regulated intracellular proteolysis of vascular endothelial growth factor receptor 1. Journal of Biological Chemistry 281 3604-3613. (doi:10.1074/jbc.M507401200)

Chen L, Fan R, Huang X, Xu H \& Zhang X 2011 Decreased concentrations of pigment epithelium-derived factor in peritoneal fluid of patients with endometriosis. Fertility and Sterility 95 1798-1800. (doi:10.1016/ j.fertnstert.2010.10.042)

Chen L, Fan R, Huang X, Xu H \& Zhang X 2012 Reduced levels of serum pigment epithelium-derived factor in women with endometriosis. Reproductive Sciences 19 64-69. (doi:10.1177/1933719111413300)

Cheng Q, Xia W, Yang S, Ye P, Mei M, Song Y, Luo M \& Li Q 2013 Association of serum pigment epithelium-derived factor with highsensitivity C-reactive protein in women with polycystic ovary syndrome. Journal of Endocrinological Investigation 36 632-635. (doi:10.1007/ BF03346755)

Cheung LW, Au SC, Cheung AN, Ngan HY, Tombran-Tink J, Auersperg N \& Wong AS 2006 Pigment epithelium-derived factor is estrogen sensitive and inhibits the growth of human ovarian cancer and ovarian surface epithelial cells. Endocrinology 147 4179-4191. (doi:10.1210/en.20060168)

Chuderland D, Ben-Ami I, Kaplan-Kraicer R, Grossman H, Ron-El R \& Shalgi R 2013a The role of pigment epithelium-derived factor in the pathophysiology and treatment of ovarian hyperstimulation syndrome in mice. Journal of Clinical Endocrinology and Metabolism 98 E258-E266. (doi:10.1210/jc.2012-3037)

Chuderland D, Ben-Ami I, Kaplan-Kraicer R, Grossman H, Komsky A, Satchi-Fainaro R, Eldar-Boock A, Ron-El R \& Shalgi R 2013b Hormonal regulation of pigment epithelium-derived factor (PEDF) in granulosa cells. Molecular Human Reproduction 19 72-81. (doi:10.1093/molehr/ gas046)

Chuderland D, Hasky N, Ben-Ami I, Kaplan-Kraicer R, Grossman H \& Shalgi R 2013c A physiological approach for treating endometriosis by recombinant pigment epithelium-derived factor. Human Reproduction 28 1626-1634. (doi:10.1093/humrep/det027)

Chuderland D, Ben-Ami I, Friedler S, Hasky N, Ninio-Many L, Goldberg K, Bar-Joseph H, Grossman H \& Shalgi R 2014 Hormonal regulation of pigment epithelium-derived factor (PEDF) expression in the endometrium. Molecular and Cellular Endocrinology 390 85-92. (doi:10.1016/j. mce.2014.04.006)

Das A, Mantena SR, Kannan A, Evans DB, Bagchi MK \& Bagchi IC 2009 De novo synthesis of estrogen in pregnant uterus is critical for stromal decidualization and angiogenesis. PNAS 106 12542-12547. (doi:10. 1073/pnas.0901647106)

Dawson DW, Volpert OV, Gillis P, Crawford SE, Xu H, Benedict W \& Bouck NP 1999 Pigment epithelium-derived factor: a potent inhibitor of angiogenesis. Science 285 245-248. (doi:10.1126/science.285. 5425.245)

Ferrara N 2004 Vascular endothelial growth factor: basic science and clinical progress. Endocrine Reviews 25 581-611. (doi:10.1210/er. 2003-0027)

Filleur S, Nelius T, de Riese W \& Kennedy RC 2009 Characterization of PEDF: a multi-functional serpin family protein. Journal of Cellular Biochemistry 106 769-775. (doi:10.1002/jcb.22072)

Fraser HM 2006 Regulation of the ovarian follicular vasculature. Reproductive Biology and Endocrinology 4 18. (doi:10.1186/14777827-4-18)

Fraser HM \& Lunn SF 2000 Angiogenesis and its control in the female reproductive system. British Medical Bulletin 56 787-797. (doi:10.1258/ 0007142001903364)

Girling JE \& Rogers PA 2005 Recent advances in endometrial angiogenesis research. Angiogenesis 8 89-99. (doi:10.1007/s10456-005-9006-9)

Girling JE \& Rogers PA 2009 Regulation of endometrial vascular remodelling: role of the vascular endothelial growth factor family and the angiopoietin-TIE signalling system. Reproduction 138 883-893. (doi:10.1530/REP-09-0147)

Girling JE, Lederman FL, Walter LM \& Rogers PA 2007 Progesterone, but not estrogen, stimulates vessel maturation in the mouse endometrium. Endocrinology 148 5433-5441. (doi:10.1210/en.2007-0856)

Gomez R, Simon C, Remohi J \& Pellicer A 2002 Vascular endothelial growth factor receptor-2 activation induces vascular permeability in hyperstimulated rats, and this effect is prevented by receptor blockade. Endocrinology 143 4339-4348. (doi:10.1210/en.2002220204)

Gomez R, Ferrero H, Delgado-Rosas F, Gaytan M, Morales C, Zimmermann RC, Simon C, Gaytan F \& Pellicer A 2011 Evidences for the existence of a low dopaminergic tone in polycystic ovarian syndrome: implications for OHSS development and treatment. Journal of Clinical Endocrinology and Metabolism 96 2484-2492. (doi:10.1210/jc. 2011-0075)

Gruemmer R, Klein-Hitpass L \& Neulen J 2005 Regulation of gene expression in endothelial cells: the role of human follicular fluid. Journal of Molecular Endocrinology 34 37-46. (doi:10.1677/jme. 1.01589)

Heryanto B \& Rogers PA 2002 Regulation of endometrial endothelial cell proliferation by oestrogen and progesterone in the ovariectomized mouse. Reproduction 123 107-113. (doi:10.1530/rep.0.1230107)

Humaidan P, Bredkjaer HE, Bungum L, Bungum M, Grondahl ML, Westergaard L \& Andersen CY $2005 \mathrm{GnRH}$ agonist (buserelin) or hCG for ovulation induction in GnRH antagonist IVF/ICSI cycles: a prospective randomized study. Human Reproduction 20 1213-1220. (doi:10.1093/humrep/deh765)

Humaidan P, Quartarolo J \& Papanikolaou EG 2010 Preventing ovarian hyperstimulation syndrome: guidance for the clinician. Fertility and Sterility 94 389-400. (doi:10.1016/j.fertnstert.2010.03.028) 
Joham AE, Teede HJ, Hutchison SK, Stepto NK, Harrison CL, Strauss BJ, Paul E \& Watt MJ 2012 Pigment epithelium-derived factor, insulin sensitivity, and adiposity in polycystic ovary syndrome: impact of exercise training. Obesity 20 2390-2396. (doi:10.1038/oby. 2012.135)

Johns A, Freay AD, Fraser W, Korach KS \& Rubanyi GM 1996 Disruption of estrogen receptor gene prevents $17 \beta$ estradiol-induced angiogenesis in transgenic mice. Endocrinology 137 4511-4513.

Kampfer C, Saller S, Windschuttl S, Berg D, Berg U \& Mayerhofer A 2014 Pigment-epithelium derived factor (PEDF) and the human ovary: a role in the generation of ROS in granulosa cells. Life Sciences 97 129-136. (doi:10.1016/j.Ifs.2013.12.007)

Katakami N, Kaneto H, Yamasaki Y \& Matsuhisa M 2008 Increased serum pigment epithelium-derived factor levels in type 1 diabetic patients with diabetic retinopathy. Diabetes Research and Clinical Practice 81 e4-e7. (doi:10.1016/j.diabres.2008.03.009)

Kuenen BC, Tabernero J, Baselga J, Cavalli F, Pfanner E, Conte PF, Seeber S, Madhusudan S, Deplanque G, Huisman H et al. 2003 Efficacy and toxicity of the angiogenesis inhibitor SU5416 as a single agent in patients with advanced renal cell carcinoma, melanoma, and soft tissue sarcoma. Clinical Cancer Research 9 1648-1655.

Laschke MW, Giebels C \& Menger MD 2011 Vasculogenesis: a new piece of the endometriosis puzzle. Human Reproduction Update 17 628-636. (doi:10.1093/humupd/dmr023)

Lash GE, Innes BA, Drury JA, Robson SC, Quenby S \& Bulmer JN 2012 Localization of angiogenic growth factors and their receptors in the human endometrium throughout the menstrual cycle and in recurrent miscarriage. Human Reproduction 27 183-195. (doi:10.1093/humrep/ der376)

Lecke SB, Morsch D \& Spritzer PM 2013 Circulating levels and subcutaneous adipose tissue gene expression of pigment epitheliumderived factor in polycystic ovary syndrome and normal women: a case control study. Reproductive Biology and Endocrinology 11 77. (doi:10. 1186/1477-7827-11-77)

Lockwood CJ 2011 Mechanisms of normal and abnormal endometrial bleeding. Menopause 18 408-411. (doi:10.1097/gme.0b013e31 820bf288)

Maik-Rachline G \& Seger R 2006 Variable phosphorylation states of pigment-epithelium-derived factor differentially regulate its function. Blood 107 2745-2752. (doi:10.1182/blood-2005-06-2547)

Maik-Rachline G, Shaltiel S \& Seger R 2005 Extracellular phosphorylation converts pigment epithelium-derived factor from a neurotrophic to an antiangiogenic factor. Blood 105 670-678. (doi:10.1182/blood-200404-1569)

Manalo KB, Choong PF, Becerra SP \& Dass CR 2011 Pigment epitheliumderived factor as an anticancer drug and new treatment methods following the discovery of its receptors: a patent perspective. Expert Opinion on Therapeutic Patents 21 121-130. (doi:10.1517/13543776. 2011.545347)

Mansour G, Sharma RK, Agarwal A \& Falcone T 2010 Endometriosisinduced alterations in mouse metaphase II oocyte microtubules and chromosomal alignment: a possible cause of infertility. Fertility and Sterility 94 1894-1899. (doi:10.1016/j.fertnstert.2009.09.043)

May KE, Conduit-Hulbert SA, Villar J, Kirtley S, Kennedy SH \& Becker CM 2010 Peripheral biomarkers of endometriosis: a systematic review. Human Reproduction Update 16 651-674. (doi:10.1093/humupd/ dmq009)

Nandi A, Chen Z, Patel R \& Poretsky L 2014 Polycystic ovary syndrome. Endocrinology and Metabolism Clinics of North America 43 123-147. (doi:10.1016/j.ecl.2013.10.003)

Notari L, Arakaki N, Mueller D, Meier S, Amaral J \& Becerra SP 2010 Pigment epithelium-derived factor binds to cell-surface $\mathrm{F}_{1}$-ATP synthase. FEBS Journal 277 2192-2205. (doi:10.1111/j.1742-4658.2010.07641.x)

Ohno-Matsui K, Morita I, Tombran-Tink J, Mrazek D, Onodera M, Uetama T, Hayano M, Murota SI \& Mochizuki M 2001 Novel mechanism for age-related macular degeneration: an equilibrium shift between the angiogenesis factors VEGF and PEDF. Journal of Cellular Physiology 189 323-333. (doi:10.1002/jcp.10026)

Osz K, Ross M \& Petrik J 2014 The thrombospondin-1 receptor CD36 is an important mediator of ovarian angiogenesis and folliculogenesis. Reproductive Biology and Endocrinology 12 21. (doi:10.1186/14777827-12-21)
Palmieri D, Watson JM \& Rinehart CA 1999 Age-related expression of PEDF/EPC-1 in human endometrial stromal fibroblasts: implications for interactive senescence. Experimental Cell Research 247 142-147. (doi:10.1006/excr.1998.4341)

Phan B, Rakenius A, Pietrowski D, Bettendorf H, Keck C \& Herr D 2006 hCG-dependent regulation of angiogenic factors in human granulosa lutein cells. Molecular Reproduction and Development 73 878-884.

Pollina EA, Legesse-Miller A, Haley EM, Goodpaster T, RandolphHabecker J \& Coller HA 2008 Regulating the angiogenic balance in tissues. Cell Cycle 7 2056-2070. (doi:10.4161/cc.7.13.6240)

Popp N, Chu XK, Shen D, Tuo J \& Chan CC 2013 Evaluating potential therapies in a mouse model of focal retinal degeneration with age-related macular degeneration (AMD)-like lesions. Journal of Clinical \& Experimental Ophthalmology 41000296.

Sheikpranbabu S, Ravinarayanan H, Elayappan B, Jongsun P \& Gurunathan S 2010 Pigment epithelium-derived factor inhibits vascular endothelial growth factor-and interleukin-1 $\beta$-induced vascular permeability and angiogenesis in retinal endothelial cells. Vascular Pharmacology 52 84-94. (doi:10.1016/j.vph.2009.12.002)

Shimizu T, Hoshino Y, Miyazaki H \& Sato E 2012 Angiogenesis and microvasculature in the female reproductive organs: physiological and pathological implications. Current Pharmaceutical Design 18 303-309. (doi:10.2174/138161212799040367)

Simonovic M, Gettins PG \& Volz K 2001 Crystal structure of human PEDF, a potent anti-angiogenic and neurite growth-promoting factor. PNAS $\mathbf{9 8}$ 11131-11135. (doi:10.1073/pnas.211268598)

Smith SK 2001 Regulation of angiogenesis in the endometrium. Trends in Endocrinology and Metabolism 12 147-151. (doi:10.1016/S10432760(01)00379-4)

Soares SR 2011 Etiology of OHSS and use of dopamine agonists. Fertility and Sterility 97 517-522. (doi:10.1016/j.fertnstert.2011.12.046)

Soares SR, Martinez-Varea A, Hidalgo-Mora JJ \& Pellicer A 2012 Pharmacologic therapies in endometriosis: a systematic review. Fertility and Sterility 98 529-555. (doi:10.1016/j.fertnstert.2012.07.1120)

Steele FR, Chader GJ, Johnson LV \& Tombran-Tink J 1993 Pigment epithelium-derived factor: neurotrophic activity and identification as a member of the serine protease inhibitor gene family. PNAS 90 1526-1530. (doi:10.1073/pnas.90.4.1526)

Sun Y, Che X, Zhu L, Zhao M, Fu G, Huang X, Xu H, Hu F \& Zhang X 2012 Pigment epithelium derived factor inhibits the growth of human endometrial implants in nude mice and of ovarian endometriotic stromal cells in vitro. PLoS ONE 7 e45223. (doi:10.1371/journal.pone.0045223)

Tempel C, Gilead A \& Neeman M 2000 Hyaluronic acid as an anti-angiogenic shield in the preovulatory rat follicle. Biology of Reproduction 63 134-140. (doi:10.1095/biolreprod63.1.134)

Tesone M, Stouffer RL, Borman SM, Hennebold JD \& Molskness TA 2005 Vascular endothelial growth factor (VEGF) production by the monkey corpus luteum during the menstrual cycle: isoform-selective messenger RNA expression in vivo and hypoxia-regulated protein secretion in vitro. Biology of Reproduction 73 927-934. (doi:10.1095/biolreprod.105. 039875)

Tombran-Tink J, Chader GG \& Johnson LV 1991 PEDF: a pigment epitheliumderived factor with potent neuronal differentiative activity. Experimental Eye Research 53 411-414. (doi:10.1016/0014-4835(91)90248-D)

Torry DS, Leavenworth J, Chang M, Maheshwari V, Groesch K, Ball ER \& Torry RJ 2007 Angiogenesis in implantation. Journal of Assisted Reproduction and Genetics 24 303-315. (doi:10.1007/s10815-0079152-7)

Volpert OV, Zaichuk T, Zhou W, Reiher F, Ferguson TA, Stuart PM, Amin M \& Bouck NP 2002 Inducer-stimulated Fas targets activated endothelium for destruction by anti-angiogenic thrombospondin-1 and pigment epithelium-derived factor. Nature Medicine 8 349-357. (doi:10.1038/ nm0402-349)

Wang JJ, Zhang SX, Mott R, Chen Y, Knapp RR, Cao W \& Ma JX 2008 Antiinflammatory effects of pigment epithelium-derived factor in diabetic nephropathy. American Journal of Physiology. Renal Physiology 294 F1166-F1173. (doi:10.1152/ajprenal.00375.2007)

Weigelt B \& Banerjee S 2012 Molecular targets and targeted therapeutics in endometrial cancer. Current Opinion in Oncology 24 554-563. (doi:10. 1097/CCO.0b013e328354e585)

Yamagishi S, Nakamura K, Ueda S, Kato S \& Imaizumi T 2005 Pigment epithelium-derived factor (PEDF) blocks angiotensin II signaling in 
endothelial cells via suppression of NADPH oxidase: a novel antioxidative mechanism of PEDF. Cell Tissue Research 320 437-445. (doi:10.1007/s00441-005-1094-8)

Yang H, Cheng R, Liu G, Zhong Q, Li C, Cai W, Yang Z, Ma J, Yang X \& Gao G 2009 PEDF inhibits growth of retinoblastoma by anti-angiogenic activity. Cancer Science 100 2419-2425. (doi:10.1111/j.1349-7006.2009.01332.x)

Yang S, Li Q, Zhong L, Song Y, Tian B, Cheng Q, Qing H, Xia W, Luo M \& Mei M 2011 Serum pigment epithelium-derived factor is elevated in women with polycystic ovary syndrome and correlates with insulin resistance. Journal of Clinical Endocrinology and Metabolism 96 831-836. (doi:10.1210/jc.2010-2140)

Zhao MD, Sun YM, Fu GF, Du YZ, Chen FY, Yuan H, Zheng CH, Zhang XM \& Hu FQ 2012 Gene therapy of endometriosis introduced by polymeric micelles with glycolipid-like structure. Biomaterials 33 634-643. (doi:10.1016/j.biomaterials.2011.09.077) de Ziegler D, Borghese B \& Chapron C 2010 Endometriosis and infertility: pathophysiology and management. Lancet 376 730-738. (doi:10.1016/ S0140-6736(10)60490-4)

de Ziegler D, Streuli I, Gayet V, Frydman N, Bajouh O \& Chapron C 2012 Retrieving oocytes from small non-stimulated follicles in polycystic ovary syndrome (PCOS): in vitro maturation (IVM) is not indicated in the new GnRH antagonist era. Fertility and Sterility 98 290-293. (doi:10.1016/j. fertnstert.2012.06.043)

Received 13 May 2014

First decision 24 June 2014

Revised manuscript received 10 July 2014

Accepted 21 July 2014 